\title{
Long term risk of invasive cancer after treatment for cervical intraepithelial neoplasia grade 3: population based cohort study
}

Björn Strander, senior consultant, ${ }^{1}$ Agneta Andersson-Ellström, senior consultant, ${ }^{1}$ lan Milsom, professor, ${ }^{1}$
Pär Sparén, professor of medical epidemiology ${ }^{2}$

${ }^{1}$ Department of Obstetrics and Gynecology, Sahlgren's Academy, University of Gothenburg, SU/Östra sjukhuset, SE-416 85 , Sweden

${ }^{2}$ Department of Medical Epidemiology and Biostatistics, Karolinska Institutet, Stockholm, Sweden

Correspondence to: B Strander, Oncology Center, Sahlgren's University Hospital, SE-413 45 Gothenburg, Sweden bjorn.strander@oc.gu.se

\section{ABSTRACT}

Objective To study the long term risk of invasive cancer of the cervix or vagina after treatment for cervical intraepithelial neoplasia grade 3.

Design Prospective cohort study.

Setting Swedish cancer registry.

Participants All women in Sweden with severe dysplasia or cervical carcinoma in situ (equivalent to cervical intraepithelial neoplasia grade 3) treated during 19582002 ( $n=132$ 493) contributing 2315724 woman years. Main outcome measures Standardised incidence ratios with risk of cancer in the Swedish general female

disease. Although most women treated for high grade dysplasias are protected from invasive cervical cancer, reports have shown an increased risk for high grade dysplasia and for cervical cancer among treated women. ${ }^{1-5}$ Knowledge about the risk of invasive cancer after treatment is important as a basis for follow-up programmes. Even with vaccination of young females against certain high risk types of human papillomavirus, surveillance after treatment of high grade cervical lesions will still be required for the foreseeable future.

It is possible to analyse the efficacy and potential weaknesses of screening programmes using data from population as reference, and relative risks in multivariable log-linear regression model, with internal references.

Results Women with previous cervical intraepithelial neoplasia grade 3 had an increased risk of invasive cervical cancer compared with the general female population (standardised incidence ratio $2.34,95 \%$ confidence interval 2.18 to 2.50 ). The increased risk showed a decreasing trend with time since diagnosis for women treated later than 1970 but the risk was still increased after 25 years. An effect of age was found, with an accentuated increase in risk for women aged more than 50 . The excess risk for cervical cancer associated with previous cervical intraepithelial neoplasia grade 3 has steadily increased since 1958 . For vaginal cancer the standardised incidence ratio was 6.82 (5.61 to 8.21) but this decreased to 2.65 after 25 years. Adjustments in the multivariable log-linear regression model did not substantially alter these results.

Conclusions Women previously treated for cervical intraepithelial neoplasia grade 3 are at an increased risk of developing invasive cervical cancer and vaginal cancer. This risk has increased since the 1960 s and is accentuated in women aged more than 50 . The risk is still increased 25 years after treatment.

\section{INTRODUCTION}

The principle behind population based screening for cervical cancer is the detection and treatment of precancerous lesions to prevent the development of cervical cancer. Many countries and settings also offer follow-up programmes to find and treat residual or recurrent the national Swedish cancer register, which was established in 1958, eight years before the first regional screening programme was introduced. Since the foundation of the cancer register it has been mandatory to report all cancers as well as some precancerous lesions, such as cervical carcinoma in situ. The reporting is double-both pathologists and clinicians report the cases - and regional cancer registers follow up all discrepancies and unclear cases. The coverage and quality of the data are high. ${ }^{67}$

We investigated whether Swedish women treated for severe dysplasia or cervical carcinoma in situ have an excess risk of cervical and vaginal cancers.

\section{METHODS}

In November 2005 we retrieved all histopathology reports of cervical carcinoma in situ, or severe dysplasia bordering on cervical carcinoma in situ, from the Swedish cancer register for 1958-2002. These diagnoses are equivalent to cervical intraepithelial neoplasia grade 3 , and the register stipulates obligatory reporting of them. The register includes dates of death and emigration through linkages to the national Swedish causes of death register and national Swedish population register, respectively. We used the patients' unique registration number to link their details to the cancer register; 881 women had a diagnosis of invasive cervical cancer and 111 women had a diagnosis of vaginal cancer. Lesions of both the external part of the cervix (portio) and the vagina are classified as cervical and lesions of both the vulva and vagina are classified as vulval. 


\section{Statistical analysis}

For women with an initial diagnosis of cervical intraepithelial neoplasia grade 3 we determined person time at risk and the number of observed and expected cervical cancers according to the yearly incidence, by five year age groups, from the general female population, using Epicure version 2.1 (Hirosoft, Seattle, Washington). We calculated standardised incidence ratios with $95 \%$ confidence intervals using SAS version 9. To account for prevalent cancers in the cohort we excluded the first year of follow-up from the analyses. We calculated the absolute risk changes, presented as difference in incidence, as the incidence-(incidence/standardised incidence ratio). These analyses were also done separately for the number of observed and expected squamous cell cancers, adenocarcinomas or adenosquamous cancers of the cervix, and vaginal cancer. For multivariable regression analyses we assumed that the observed number of cases followed a Poisson distribution, and we weighted the number of observed cases by the log of the number of expected cases. These analyses were carried out using SAS version 9.

\section{RESULTS}

Overall, 132493 women had a diagnosis of cervical carcinoma in situ or severe dysplasia (equivalent to cervical intraepithelial neoplasia grade 3) recorded in the Swedish cancer register during 1958-2000, contributing 2315724 woman years. Of these women, 881 had a diagnosis of invasive cervical cancer more than one year after treatment for cervical intraepithelial neoplasia grade 3. The overall standardised incidence ratio for women with previous cervical intraepithelial neoplasia grade 3 to develop invasive cervical cancer was 2.30 (95\% confidence interval 2.15 to 2.46) compared with the general female population (table 1). The risk was significantly increased in all

\begin{tabular}{|c|c|c|c|c|c|c|c|c|c|c|}
\hline \multirow[b]{2}{*}{ Variables } & \multicolumn{5}{|c|}{ Cervical cancer } & \multicolumn{5}{|c|}{ Vaginal cancer } \\
\hline & $\begin{array}{l}\text { No of } \\
\text { cases }\end{array}$ & $\begin{array}{l}\text { Expec- } \\
\text { ted No }\end{array}$ & $\begin{array}{l}\text { Woman } \\
\text { years }\end{array}$ & $\operatorname{SIR}(95 \% \mathrm{CI})$ & $\begin{array}{c}\text { Change in } \\
\text { incidence/ } \\
100000\end{array}$ & $\begin{array}{l}\text { No of } \\
\text { cases }\end{array}$ & $\begin{array}{l}\text { Expec- } \\
\text { ted No }\end{array}$ & $\begin{array}{l}\text { Woman } \\
\text { years }\end{array}$ & $\operatorname{SIR}(95 \% \mathrm{Cl})$ & $\begin{array}{c}\text { Change in } \\
\text { incidence/ } \\
100000\end{array}$ \\
\hline All cases & 881 & 382 & 2315724 & 2.30 (2.15 to 2.46$)$ & 21.5 & 111 & 16.28 & 2324157 & $6.82(5.61$ to 8.21$)$ & 4.1 \\
\hline \multicolumn{11}{|l|}{ Birth cohort: } \\
\hline$\ll 1915$ & 94 & 13 & 52583 & 6.99 (5.65 to 8.55$)$ & 153.2 & 25 & 1.39 & 53069 & 17.97 (11.63 to 26.53$)$ & 44.5 \\
\hline $1915-29$ & 225 & 84 & 376018 & 2.66 (2.33 to 3.03$)$ & 37.3 & 44 & 6.45 & 377678 & 6.83 (4.96 to 9.16$)$ & 9.9 \\
\hline $1930-9$ & 166 & 75 & 476699 & 2.21 (1.89 to 2.57 ) & 19.1 & 18 & 3.60 & 478550 & 5.00 (2.96 to 7.91$)$ & 3.0 \\
\hline $1940-9$ & 191 & 113 & 761352 & 1.69 (1.46 to 1.94$)$ & 10.2 & 16 & 3.45 & 763960 & $4.64(2.65$ to 7.53$)$ & 1.6 \\
\hline $1950-9$ & 157 & 73 & 462532 & 2.13 (1.81 to 2.49$)$ & 18.0 & 7 & 1.16 & 463950 & $6.02(2.42$ to 12.41$)$ & 1.3 \\
\hline $1960-9$ & 47 & 20 & 163772 & 2.28 (1.67 to 3.03 ) & 13.8 & 1 & 0.23 & 186950 & 4.34 (0.11 to 24.18$)$ & 0.4 \\
\hline$\geq 1970$ & 1 & 1 & 22768 & $0.58(0.01$ to 3.22$)$ & & & & & & \\
\hline \multicolumn{11}{|c|}{$\begin{array}{l}\text { Age at diagnosis of } \\
\text { CIN } 3 \text { (years): }\end{array}$} \\
\hline$<20$ & 3 & 3 & 29464 & 0.93 (0.19 to 2.73$)$ & -0.8 & 0 & 0.04 & 29507 & 0 (0 to 70.78$)$ & 0 \\
\hline $20-29$ & 158 & 114 & 779005 & 1.38 (1.17 to 1.61$)$ & 5.6 & 12 & 2.12 & 780702 & 5.67 (2.93 to 9.90$)$ & 1.3 \\
\hline $30-39$ & 305 & 147 & 898004 & 2.07 (1.84 to 2.31 ) & 17.6 & 14 & 5.01 & 901839 & 2.80 (1.53 to 4.69$)$ & 1.0 \\
\hline $40-49$ & 203 & 85 & 456020 & 2.37 (2.05 to 2.72 ) & 25.7 & 40 & 5.70 & 457502 & 7.02 (5.01 to 9.55$)$ & 7.5 \\
\hline $50-59$ & 123 & 23 & 114626 & 5.19 (4.32 to 6.20$)$ & 86.6 & 21 & 2.20 & 115603 & $9.54(5.91$ to 14.59$)$ & 16.3 \\
\hline $60-69$ & 65 & 6 & 29995 & 10.24 (7.90 to 13.05$)$ & 195.5 & 13 & 0.87 & 30364 & 15.02 (8.00 to 25.68 ) & 40.0 \\
\hline 70-79 & 22 & 1 & 7743 & $14.62(9.16$ to 22.13$)$ & 264.7 & 9 & 0.31 & 7776 & 29.39 (13.44 to 55.78$)$ & 111.8 \\
\hline$\geq 80$ & 2 & 0 & 868 & 16.1 (1.95 to 58.16$)$ & 216.2 & 2 & 0.04 & 864 & $50.36(6.10$ to 181.93$)$ & 226.9 \\
\hline \multicolumn{11}{|c|}{ Period of diagnosis: } \\
\hline $1958-70$ & 241 & 127 & 647924 & 1.89 (1.66 to 2.14$)$ & 17.5 & 47 & 6.93 & 650115 & 6.79 (4.99 to 9.02$)$ & 6.2 \\
\hline $1971-80$ & 313 & 145 & 925035 & 2.15 (1.92 to 2.40$)$ & 18.1 & 29 & 6.05 & 928394 & 4.79 (3.21 to 6.88$)$ & 2.5 \\
\hline $1981-90$ & 244 & 85 & 569220 & 2.86 (2.52 to 3.25$)$ & 27.9 & 27 & 2.59 & 571523 & 10.43 (6.88 to 15.18$)$ & 4.3 \\
\hline $1991-2002$ & 83 & 23 & 173545 & $3.52(2.80$ to 4.36$)$ & 34.2 & 8 & 0.71 & 174125 & $11.24(4.85$ to 22.15$)$ & 4.2 \\
\hline \multicolumn{11}{|c|}{$\begin{array}{l}\text { Time since diagnosis } \\
\text { (years): }\end{array}$} \\
\hline $1-<2$ & 71 & 21 & 126772 & $3.28(2.56$ to 4.13$)$ & 17.7 & 10 & 0.35 & 126934 & 28.43 (13.64 to 52.29$)$ & 7.6 \\
\hline $2-4$ & 169 & 62 & 357979 & $2.70(2.31$ to 3.14$)$ & 38.9 & 15 & 1.13 & 358671 & 13.31 (7.45 to 21.96$)$ & 3.9 \\
\hline $5-9$ & 242 & 92 & 528115 & 2.61 (2.29 to 2.96$)$ & 29.7 & 26 & 2.14 & 529757 & 12.15 (7.94 to 17.80$)$ & 4.5 \\
\hline $10-14$ & 168 & 75 & 446732 & 2.23 (1.90 to 2.59 ) & 28.3 & 20 & 2.50 & 448548 & 8.01 (4.89 to 12.37$)$ & 3.9 \\
\hline $15-19$ & 103 & 55 & 353676 & 1.84 (1.50 to 2.24$)$ & 20.7 & 14 & 2.79 & 355321 & 5.01 (2.74 to 8.41$)$ & 3.2 \\
\hline $20-24$ & 66 & 38 & 253887 & 1.73 (1.34 to 2.20 ) & 13.3 & 14 & 2.85 & 255076 & 4.91 (2.69 to 8.24$)$ & 4.4 \\
\hline$\geq 25$ & 62 & 36 & 248563 & 1.72 (1.32 to 2.20$)$ & 11.0 & 12 & 4.52 & 249851 & $2.65(1.37$ to 4.64$)$ & 3.0 \\
\hline
\end{tabular}

$\mathrm{SIR}=$ standardised incidence ratio. SIR and change in absolute risk expressed as change in incidence per 100000 woman years for whole population and stratified for birth cohort, age at diagnosis of CIN 3, period of diagnosis, and time (years) since diagnosis and the detection of invasive cancer. 
birth cohorts, except for the latest (women born after 1969), for whom the risk did not differ from unity. The most noticeable increase was in the earliest cohort (women born before 1915). The risk was increased in all ages when treated aged more than 20 , with an accelerated increase after age 50. For each decade since the 1960 s the time trend was of increasing risk, with a standardised incidence ratio of developing invasive cancer after treatment for cervical intraepithelial neoplasia grade 3 almost twice as high if treatment was undertaken during 1991-2000 compared with 1958-70.

Overall, 746 of the 881 women with cervical epithelial cancer had squamous epithelial cancer (85\%), 131 had adenocarcinoma or adenosquamous carcinoma (15\%), and four had other diagnoses. The standardised incidence ratio for developing invasive squamous cell cervical cancer was slightly higher $(2.49,2.32$ to 2.68$)$ than that for all cervical cancers, but the pattern in different periods, age at diagnosis of and treatment for cervical intraepithelial neoplasia grade 3 , and time since diagnosis did not differ from the overall data for all invasive cervical cancer (data not shown).

The risk of developing adenocarcinoma or adenosquamous carcinoma also increased (standardised

$\overline{\text { Table } 2 \text { | Relative risks compared with internal references of invasive cervical cancer and vaginal }}$ cancer among women with previous cervical intraepithelial neoplasia grade 3 (CIN 3)

\begin{tabular}{|c|c|c|}
\hline Variables & $\begin{array}{c}\text { Relative risk }(95 \% \mathrm{Cl}) \\
\text { of cervical cancer }\end{array}$ & $\begin{array}{c}\text { Relative risk }(95 \% \mathrm{Cl}) \\
\text { of vaginal cancer }\end{array}$ \\
\hline \multicolumn{3}{|c|}{ Age at diagnosis of CIN 3: } \\
\hline$<20$ & $0.49(0.16$ to 1.53$)$ & * \\
\hline $20-29$ & $0.67(0.55$ to 0.81$)$ & 2.25 (1.04 to 4.87$)$ \\
\hline 30-39† & $1.00(1.00$ to 1.00$)$ & $1.00(1.00$ to 1.00$)$ \\
\hline $40-49$ & $1.23(1.03$ to 1.48$)$ & 2.41 (1.31 to 4.45$)$ \\
\hline $50-59$ & 2.67 (2.16 to 3.29$)$ & 2.90 (1.47 to 5.73$)$ \\
\hline $60-69$ & 4.75 (3.63 to 6.21$)$ & 3.81 (1.77 to 8.19$)$ \\
\hline $70-79$ & 6.00 (3.88 to 9.28$)$ & $6.44(2.71$ to 15.33$)$ \\
\hline$\geq 80$ & 6.38 (1.58 to 25.70$)$ & $9.72(2.15$ to 44.04$)$ \\
\hline P for trend & $<0.001$ & $<0.001$ \\
\hline \multicolumn{3}{|c|}{ Period of diagnosis: } \\
\hline 1958-70† & $1.00(1.00$ to 1.00$)$ & 1.00 (1.00 to 1.00$)$ \\
\hline $1971-80$ & 1.37 (1.27 to 1.07$)$ & 0.54 (0.33 to 0.87$)$ \\
\hline $1981-90$ & $1.76(1.63$ to 1.35$)$ & $0.78(0.46$ to 1.31$)$ \\
\hline $1991-2000$ & 1.80 (1.65 to 1.27$)$ & $0.46(0.20$ to 1.04$)$ \\
\hline P for trend & $<0.001$ & 0.007 \\
\hline \multicolumn{3}{|c|}{ Time since diagnosis (years): } \\
\hline $1-<2$ & $1.16(0.88$ to 1.54$)$ & $2.09(0.94$ to 4.65$)$ \\
\hline $2-4 \dagger$ & $1.00(1.00$ to 1.00$)$ & $1.00(1.00$ to 1.00$)$ \\
\hline $5-9$ & $1.03(0.85$ to 1.26$)$ & $0.95(0.50$ to 1.80$)$ \\
\hline $10-14$ & $0.94(0.76$ to 1.18$)$ & $0.66(0.33$ to 1.31$)$ \\
\hline $15-19$ & 0.84 (0.65 to 1.08$)$ & $0.45(0.21$ to 0.95$)$ \\
\hline $20-24$ & $0.86(0.64$ to 1.15$)$ & $0.44(0.20$ to 0.96$)$ \\
\hline$\geq 25$ & $0.91(0.67$ to 1.23$)$ & 0.21 (0.09 to 0.47$)$ \\
\hline P for trend & 0.04 & $<0.001$ \\
\hline P for interaction $\ddagger$ & $<0.001$ & 0.45 \\
\hline
\end{tabular}

Result of multivariable log-linear regression, with adjustment for age at diagnosis of CIN 3, period of diagnosis, and time (years) since diagnosis and the detection of invasive cancer.

*This category was collapsed with 20-29 years owing to lack of cases.

tReference category.

łInteraction between period of diagnosis and time since diagnosis. incidence ratio $1.62,95 \%$ confidence interval 1.36 to 1.93). The risk seemed to be inflated particularly for women treated for cervical intraepithelial neoplasia grade 3 in the 1990s, and time since diagnosis had no effect (data not shown).

When controlling for period of diagnosis and time since diagnosis in the multivariable regression model, a trend $(\mathrm{P}<0.001)$ was found of increasing risk of cervical cancer with increasing age at diagnosis, with a noticeable acceleration after age 50 (table 2). The time trend of increased risk for each decade since the 1960 s also remained in the multivariable regression model $(\mathrm{P}<0.001)$, with the risk of developing invasive cancer almost twice as high if treatment for cervical intraepithelial neoplasia grade 3 was undertaken during 1991-2000 compared with 1958-70. A slight decrease in relative risk was found by time since diagnosis $(\mathrm{P}=0.04)$, although none of the risk estimates significantly deviated from unity. Further analysis showed a significant interaction between period of diagnosis and time since diagnosis $(\mathrm{P}<0.001)$. Stratifying for time period showed an increased risk of acquiring cervical cancer with time after treatment during 1958-70, whereas the risk decreased with time for period of diagnosis after 1970 (table 3): standardised incidence ratio 2.16 (1.51 to 2.59) up to 15 years after treatment and 1.50 (1.07 to 2.10$)$ up to 25 years after treatment.

In the multivariable regression model the risk for adenocarcinoma or adenosquamous carcinoma also increased with age at diagnosis of cervical intraepithelial neoplasia grade 3 as well as if the period of diagnosis was after 1970 (data not shown).

\section{Vaginal cancer}

The risk of developing vaginal cancer, a rare disease, after treatment for cervical intraepithelial neoplasia grade 3 was small in absolute terms - 111 cases, with $95 \%$ being squamous epithelial cancer: incidence 5/100 000 woman years. The observed number was, however, almost seven times higher than expected. The standardised incidence ratios showed an increased risk with age and with period of diagnosis but a decreased risk with time since diagnosis (table 1). In the multivariable regression analysis, however, a decreasing risk was found with period of treatment (table 2). The decreased risk with time since diagnosis persisted and after 25 years it was one fifth of the risk in the reference follow-up period (2-4 years). No evidence was found of an interaction between period of diagnosis and time since diagnosis $(\mathrm{P}=0.45)$.

To account for possible misclassification of cervical cancers as vaginal cancers the data for cervical and vaginal cancers were pooled. Two women had both diagnoses and were censored at the time of the first diagnosis. In total, 990 cases were found (incidence rate 43/100 000 woman years) and the risk of cervical or vaginal cancer after treatment for cervical intraepithelial neoplasia grade 3 was increased 2.5 times compared with the general female population (standardised incidence ratio $2.48,2.33$ to 2.64 ). 


\section{DISCUSSION}

Women have a high excess risk of developing invasive cervical cancer after treatment for cervical carcinoma in situ or severe dysplasia bordering on cervical carcinoma in situ (equivalent to cervical intraepithelial neoplasia grade 3). The risk has increased since the 1960s and is almost twice as high for women treated in the 1990s compared with those treated during 1958-70.

One possible explanation is differences in treatment modalities. The Swedish cancer register does not, however, include data on treatment. Over the period studied (1958-2000), however, a strong consensus throughout Sweden has been to treat women with a diagnosis of cervical intraepithelial neoplasia grade 3 and to offer intensified follow-up with cytology for at least five years. We are confident therefore that most of the cohort with a diagnosis of cervical intraepithelial neoplasia grade 3 had been treated. In the 1960s high grade cervical dysplasia was treated by hysterectomy, and cold knife conisation was considered a conservative treatment. During the 1980s more conservative modes of treatment such as cryotherapy, cauterisation, and laser vaporisation or conisation became popular. Cold knife conisation was fairly uncommon in Sweden in 1990, when large loop excision of the transformational zone was introduced. ${ }^{8}$ Large loop excision of the transformational zone is now the dominant method of treatment for dysplasia in Sweden as in the rest of Europe. This development has been favourable for preservation of fertility ${ }^{9}$ and for minimising postoperative morbidity but leaves more tissue at risk of recurrent dysplasia and possibly also undetected residual dysplasia. Women of fertile age have been treated more conservatively since the $1960 \mathrm{~s}$, and they have a considerably lower risk of cancer than older women. Despite this the changed patterns in therapy can help explain the trend over time, as the trend remained after adjustment for age in the multivariable regression model. One study looked at the influence of treatment modalities ${ }^{4}$ but did not find any significant difference in recurrence of cervical intraepithelial neoplasia or incidence of cancer between women who had undergone hysterectomy and those who were treated by conservative methods. One weakness of the study, however, was the small number of women who had had a hysterectomy.

\begin{tabular}{|c|c|c|}
\hline $\begin{array}{l}\text { Time since diagnosis } \\
\text { of CIN } 3 \text { (years) }\end{array}$ & $\begin{array}{l}\text { SIR }(95 \% \mathrm{Cl}) \text { for diagnosis } \\
\text { during } 1958-70\end{array}$ & $\begin{array}{l}\text { SIR }(95 \% \text { CI) for diagnosis } \\
\text { during 1971-2002 }\end{array}$ \\
\hline $1-<2$ & 0.62 (0.23 to 1.64$)$ & $4.42(3.48$ to 5.61$)$ \\
\hline $2-4$ & 1.17 (0.76 to 1.80$)$ & 3.32 (2.83 to 3.90$)$ \\
\hline $5-9$ & 1.99 (1.50 to 2.63$)$ & 2.84 (2.46 to 3.27 ) \\
\hline $10-14$ & 2.40 (1.81 to 3.17$)$ & 2.16 (1.81 to 2.59$)$ \\
\hline $15-19$ & 2.29 (1.67 to 3.14) & 1.65 (1.29 to 2.10$)$ \\
\hline $20-24$ & 2.06 (1.46 to 2.92$)$ & 1.50 (1.07 to 2.10$)$ \\
\hline$\geq 25$ & 1.82 (1.37 to 2.43$)$ & 1.45 (0.88 to 2.41$)$ \\
\hline P for trend & 0.005 & $<0.001$ \\
\hline
\end{tabular}

Table 3 Standardised incidence ratios (SIR) for cervical cancer by time since diagnosis of cervical
A possible shift in diagnostic criteria over time must also be considered. The incidence of cervical intraepithelial neoplasia grade 3 has been stable since 1968 , however, with a $10 \%$ drop after the early 1980 s, corresponding to treatment extended to women with milder grades of dysplasia. We can also speculate that the increased prevalence of human papillomavirus infection over the years has had a greater impact on women treated for cervical intraepithelial neoplasia grade 3 compared with the general population. Cervical intraepithelial neoplasia grade 3 is to a large extent caused by persistent infection with human papillomavirus. Thus this cohort has a proved susceptibility to high risk infection, which remains as a risk factor and might make these women more vulnerable to increased exposure to the virus. The classic lifestyle risk factors for human papillomavirus infection as well as cervical cancer, such as number of partners, number of partners' partners, and cigarette smoking, may also remain throughout life in women treated for cervical intraepithelial neoplasia grade 3 and therefore constitute an increased risk despite treatment.

The increased risk of cervical cancer in the entire cohort did not decline substantially in the 25-30 years after treatment, but a stratified analysis showed opposite trends with period of diagnosis (table 3). In women treated after 1970 the trend is of decreasing standardised incidence ratios, but their risk of cervical cancer is still increased compared with that of the general population. After 10 years of follow-up the standardised incidence ratios for women with cervical intraepithelial neoplasia grade 3 treated before or after 1970 are similar.

Swedish women with no history of diagnosis of high grade dysplasia have a low risk of developing dysplasia and cancer after the age of 50. In most organised screening programmes this has justified less frequent screening or stopping screening in women around age 60. ${ }^{10}$ Those women treated for cervical intraepithelial neoplasia grade 3 are, however, still at risk. The clinical implication of our findings is that women treated for cervical intraepithelial neoplasia need special programmes for long term follow-up, with cytology and possibly testing for human papillomavirus. Stopping such a programme in women aged 60 is not justified if they were aged more than 35-40 when treated.

We have no clinical data on the women after treatment for cervical intraepithelial neoplasia grade 3 , but according to Swedish guidelines such women are offered frequent appointments for screening after treatment ${ }^{11}$ and their motivation for attending has generally been high. It is not unreasonable to assume that these women have been more closely followed up with cytology than the general population. The noticeable increase in incidence of cervical cancer for women aged more than 50 at the time of treatment could partly be due to lack of follow-up but it could also lead to questioning the follow-up programme of cytology alone, which has been customary in Sweden as elsewhere. Testing for human papillomavirus DNA has shown to be of some benefit in identifying women in 


\section{WHAT IS ALREADY KNOWN ON THIS TOPIC}

The risk of invasive cervical cancer is more than double that of the general population at least 10 years after treatment for cervical intraepithelial neoplasia grade 3

Long term incidence of vaginal cancer after treatment for cervical intraepithelial neoplasia grade 3 is poorly documented

\section{WHAT THIS STUDY ADDS}

Women are at an increased risk of invasive cervical cancer more than 25 years after treatment for cervical intraepithelial neoplasia grade 3

The risk of invasive disease is noticeably increased in women aged more than 50 when treated

The risk of vaginal cancer is increased in women treated for cervical intraepithelial neoplasia grade 3 analysis of the follow-up of women with previous cervical intraepithelial neoplasia grade 3.

The risk of vaginal cancer after treatment of cervical intraepithelial neoplasia grade 3 seems to decrease with time. After adjusting for age at diagnosis and period of diagnosis in the multivariate analysis this risk after more than 25 years seems to be only a 10 th of that 1 or 2 years after treatment, although this is still more than double that of the general population. The reason for this pattern is unclear. One possible explanation could be that vaginal dysplasias and even cancers were concomitant with cervical intraepithelial neoplasia grade 3 and that these were overlooked during treatment for cervical intraepithelial neoplasia grade 3 but found in the immediate follow-up period. No new susceptible metaplastic epithelium can develop after hysterectomy, and assuming that a large proportion of women who develop vaginal cancer after a diagnosis of cervical intraepithelial neoplasia grade 3 have undergone hysterectomy then the procedure might provide better protection than conservative treatment, something which is still to be proved. Although the number of women with vaginal cancer was small, the large increase even in absolute risk for vaginal cancer in women aged more than 60 when treated for cervical intraepithelial neoplasia grade 3 necessitates consideration of follow-up and supports follow-up even after hysterectomy. ${ }^{4}$

The strength of this study is the size of the study cohort, comprising almost 2.5 million woman years after diagnosis of cervical intraepithelial neoplasia grade 3 . This is more than four times the combined data in a recently published meta-analysis. ${ }^{4}$ Furthermore, the completeness of records in the Swedish cancer registry is high, and linkage to comprehensive records covering the entire Swedish population makes it possible to keep track of migration and deaths.

The weaknesses of this study are that we could not link the data to mode of treatment or to hysterectomies and we lacked information on how the women have been followed up. We can only speculate therefore about the influence of these modalities.

\section{Conclusion}

Women treated for cervical intraepithelial neoplasia grade 3 are at increased risk of developing invasive cancer in the remaining cervix or vagina. This risk has increased with changes in treatment modalities since the 1990s compared with treatment in the $1960 \mathrm{~s}$, is higher for women who are older ( $\geq 50$ years) at treatment, and remains increased 20 or more years after treatment compared with the general population. The question on how follow-up should be carried out is not resolved but this study implies that it has been insufficient and that prospective studies for strategies of long term follow-up after treatment of high grade cervical lesions are needed. Until we have learnt more we should at least offer women who have been treated for cervical intraepithelial neoplasia grade 3 cytological smears at regular intervals, preferably for at least 25 years, independent of age. 
Contributors: BS and IM conceived the study. BS, AAE, and PS designed the study. BS and PS analysed the data. All authors drafted and revised the manuscript. PS is guarantor.

Funding: This study was partially financed with a grant from the county of Halland, Sweden and the Gothenburg Medical Society.

Competing interests: None declared.

Ethical approval: Data retrieval was approved by the ethics committee of the Karolinska University Hospital (No 02-556)

1 Kolstad P, Klem V. Long-term follow up of 1121 cases of carcinoma in situ. Obstet Gynecol 1976;48:125-9.

2 Pettersson F, Malker B. Invasive carcinoma of the uterine cervix following diagnosis and treatment of in situ carcinoma. Record linkage study within a national cancer registry. Radiother Oncol 1989;16:115-20.

3 Soutter WP, de Barros Lopes A, Fletcher A, Monaghan JM, Duncan ID, Paraskevaidis E, et al. Invasive cervical cancer after conservative therapy for cervical intraepithelial neoplasia. Lancet 1997;349:978-80.

4 Soutter WP, Sasieni P, Panoskaltsis T. Long-term risk of invasive cervical cancer after treatment of squamous cervical intraepithelial neoplasia. Int J Cancer 2006;118:2048-55.

5 Andersson-Ellstrom A, Seidal T, Grannas M, Hagmar B. The pap-smear history of women with invasive cervical squamous carcinoma. A case-control study from Sweden. Acta Obstet Gynecol Scand 2000;79:221-6.

6 National Board of Health and Welfare. Cancer incidence in Sweden 2003. Stockholm: Socialstyrelsen, 2005.

7 Mattsson B, Wallgren A. Completeness of the Swedish Cancer Register. Non-notified cancer cases recorded on death certificates in 1978. Acta Radiol Oncol 1984;23:305-13.

8 Strander B. Hur cervixcancer blev en ovanlig sjukdom [How cancer in the uterine cervix became a rare disease]. In: Lindberg B, ed. Svensk gynekologi under ett sekel [Swedish gynaecology during one century] Uppsala: Svensk Förening för Obstetrik och Gynekologi [Swedish Society of Obstetrics and Gynecology], 2004.

9 Kyrgiou M, Koliopoulos G, Martin-Hirsch P, Arbyn M, Prendiville W, Paraskevaidis E. Obstetric outcomes after conservative treatment for intraepithelial or early invasive cervical lesions: systematic review and meta-analysis. Lancet 2006;367:489-98.

10 National Board of Health and Welfare. Gynekologisk cellprovskontroll -Förslag till screeningprogram [Guidelines for cervical screening]. Stockholm: Socialstyrelsen, 1998.
11 HARG. Arbets-och referensgrupp för Gynekologisk hälsokontroll [Committee for cervical screening]. Att förebygga cervixcancer samt vaginal och vulvacancer. Riktlinjer för diagnos, behandling och kontroll av intraepitelial neoplasi och papillomvirusinfektioner i cervix, vagina och vulva [Protecting from cervical, vaginal and vulvar cancer-guidelines]. Stockholm: Swedish Society for Obstetrics and Gynecology, 1997.

12 Zielinski GD, Bais AG, Helmerhorst TJ, Verheijen RH, de Schipper FA, Snijders PJ, et al. HPV testing and monitoring of women after treatment of CIN 3: review of the literature and meta-analysis. Obstet Gynecol Surv 2004;59:543-53.

13 Strander B, Ryd W, Wallin KL, Warleby B, Zheng B, Milsom I, et al. Does HPV-status 6-12 months after treatment of high grade dysplasia in the uterine cervix predict long term recurrence? Eur J Cancer 2007;43:1849-55.

14 Castellsague X, Diaz M, de Sanjose S, Munoz N, Herrero R, Franceschi S, et al. Worldwide human papillomavirus etiology of cervical adenocarcinoma and its cofactors: implications for screening and prevention. J Natl Cancer Inst 2006;98:303-15.

15 Bray F, Carstensen B, Moller H, Zappa M, Zakelj MP, Lawrence G, et al. Incidence trends of adenocarcinoma of the cervix in 13 European countries. Cancer Epidemiol Biomarkers Prev 2005;14:2191-9.

16 Kalliala I, Anttila A, Pukkala E, Nieminen P. Risk of cervical and other cancers after treatment of cervical intraepithelial neoplasia: retrospective cohort study. BMJ 2005;331:1183-5.

17 Daling JR, Madeleine MM, Schwartz SM, Shera KA, Carter JJ, McKnight B, et al. A population-based study of squamous cell vaginal cancer: HPV and cofactors. Gynecol Oncol 2002;84:263-70.

18 Edgren G, Sparen P. Risk of anogenital cancer after diagnosis of cervical intraepithelial neoplasia: a prospective population-based study. Lancet Oncol 2007;8:311-6.

19 Hellman K, Silfversward C, Nilsson B, Hellstrom AC, Frankendal B, Pettersson F. Primary carcinoma of the vagina: factors influencing the age at diagnosis. The Radiumhemmet series 1956-96. Int J Gynecol Cancer 2004; 14:491-501.

20 National Board of Health and Welfare. Swedish hospital discharge register 1998-2005. www.socialstyrelsen.se/Statistik/ statistikdatabas/ (accessed 14 Dec 2006).

21 Pettersson F, Bjorkholm E, Naslund I. Evaluation of screening for cervical cancer in Sweden: trends in incidence and mortality 1958 1980. Int J Epidemiol 1985;14:521-7.

Accepted: 9 September 2007 